\title{
Reputational Risk in the context of A.M. Best's Rating Analysis
}

\section{Michael Zboron}

A.M. Best Europe, 12 Arthur Street, London EC4R 9AB, U.K.

E-mail: michael.zboron@ambest.com

Reputational risk is one of the biggest threats for insurance companies. The promise to provide insurance cover or the promise to pay out an agreed sum at expiry or when an insured dies is based on the trust that a policyholder has in an insurer that it will be able and willing to honour its commitment. Any doubt in an insurer's commitment as a result of financial constraints, but also due to business practices could have a significant negative impact on its business profile. In A.M. Best's view, the management of reputational risk is intrinsically linked to an insurer's overall risk assessment and risk control strategy.

The Geneva Papers (2006) 31, 500-511. doi:10.1057/palgrave.gpp.2510088

Keywords: reputational risk; trust; financial strength rating; insurance

\section{A.M. Best's rating process}

Overview

A.M. Best's financial strength rating is an opinion of an insurer's ability to fulfill its obligations to its policyholders. The assigned rating is derived from an in-depth evaluation of a company's balance sheet strength, operating performance and business profile as compared to A.M. Best's quantitative and qualitative standards. An important component of the evaluation process requires an interactive exchange of information with the insurance company's management. In addition, opinions are also derived from the evaluation of country risk, which includes corporate and political governance, economic environment and insurance industry environment. However, a rating is not a recommendation and it is not a quality certificate (Figure 1).

\section{Interdependence of rating components}

A.M. Best's rating is an opinion about the financial strength of an insurer. The rating analysis conducted by its analysts is by nature prospective as policyholders have an interest in knowing the probability that an insurer may default on existing and future obligations. The higher the assigned financial strength rating the lower is the likelihood of default in A.M. Best's opinion. The evaluation of an insurer's balance sheet strength - as the most important rating category - is the foundation of the rating process and determines the initial direction in formulating a rating and it would be relatively easy to assess an insurer's historical balance sheet at a given date. However, as A.M. Best provides a prospective view of an insurer's financial strength, the other rating components (operating performance and business profile) are an important part of the rating analysis. The future balance sheet strength is to a larger extent dependent on an insurer's current and prospective business profile and operating performance. 


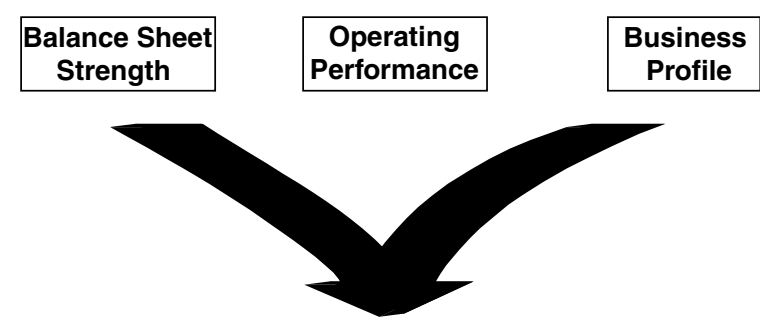

A.M. Best's Rating

Figure 1. A.M. Best's rating process. Main rating pillars.

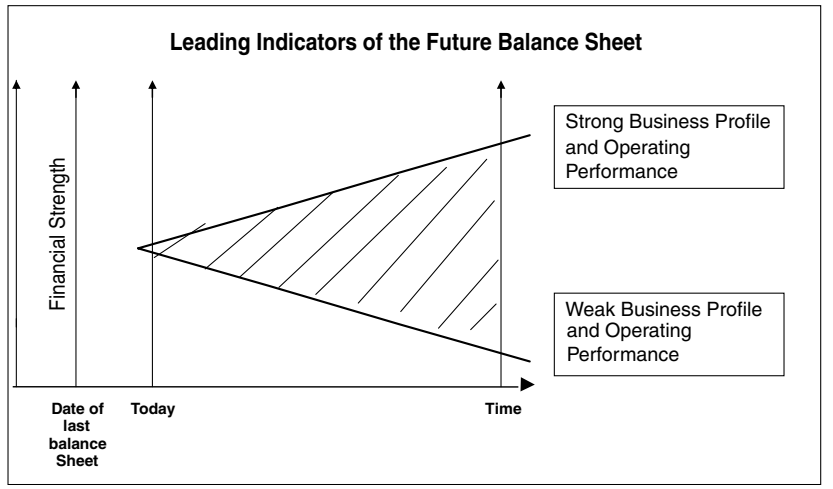

Figure 2. A.M. Best's rating process. Financial strength analysis.

An insurer which has a strong business profile is more likely to be able to adequately price the risks it writes than an insurer with a weaker business profile. This in turn enables a company to generate stronger earnings and should therefore lead to a strengthening of an insurer's balance sheet over time. On the other hand, insurers with a weaker business profile will have less pricing power, thus negatively impacting earnings. Over time, this is likely to lead to a diminishing capital base, which can then have a negative influence on the financial strength of an insurer (Figure 2).

\section{Rating components - analytical issues}

Balance sheet strength As mentioned above, the evaluation of the strength of an insurer's balance sheet is the most important rating component as it determines the company's ability to fulfill its current and ongoing obligations. The analysis comprises assessing underwriting, financial, and asset leverage, as these measure the exposure of a company's capital base to its operating and financial practices. A highly leveraged or poorly capitalized company may show a high return on equity, but may be exposed to a high risk of instability. A conservative level of leverage or capitalization enables an insurer to better withstand catastrophes, unexpected losses and adverse changes in 
underwriting results, fluctuating investment returns or investment losses, as well as changes in regulatory or economic conditions.

Underwriting leverage Underwriting leverage evaluates an insurer's exposure to underwriting risks compared to its shareholders' funds. Although this is a crude measure, it can provide an indication of an insurer's risk of pricing error in its book of business. Underwriting leverage is defined as written premiums over shareholders' funds, both on a gross and on a net basis. As part of the analysis, A.M. Best also assesses an insurer's dependence on reinsurance, which exposes a company to both credit and liquidity risk. In order to assess whether or not an individual company's underwriting leverage is prudent, a number of factors unique to the company are taken into consideration. These factors include spread of risk, quality and appropriateness of its reinsurance programme as well as adequacy of loss reserves.

Financial leverage Financial leverage measures the amount of debt on the balance sheet compared to the overall capital base. Debt, or debt-like instruments (including financial reinsurance), may place a call on an insurer's earnings and strain its cash flow and can lead to financial instability. This analysis is conducted at both the operating company and holding company levels, as regulatory restrictions do not always allow issuing debt by operating companies.

Asset leverage - quality and diversification A.M. Best also evaluates asset leverage, which measures the exposure of a company's shareholders' funds to investments, interest rates and credit risks. Investment and interest rate risks measure the credit quality and volatility associated with the company's investment portfolio and the potential impact on its balance sheet strength.

The quality and diversification of assets contribute to a company's financial stability. Invested assets (principally bonds, common stocks, mortgages and real estate) are evaluated to assess the risk of default and the potential impact on shareholders' funds if the sale of these assets occurred unexpectedly. The better the liquidity, diversification and/or quality of the assets, the less uncertainty there is in the value to be realized upon their sale and therefore the lesser the likelihood of default.

A.M. Best risk-adjusted capital model (BCAR) A company's underwriting, financial and asset leverage is also subjected to an evaluation by Best's Capital Adequacy Ratio (BCAR), which calculates the Net Required Capital to support the financial risks of the company with regard to the exposure of its investments, assets and underwriting to adverse economic and market conditions (such as a rise in interest rates, a decline in the equity markets and above normal catastrophes).

Liquidity In order to pay out claims or accrued funds at expiry, insurers need to hold sufficiently liquid investments. A high degree of liquidity enables an insurer to meet unexpected needs for cash without the untimely sale of investments or fixed assets, which may result in substantial realized losses due to temporary market conditions and/or tax consequences. In order to measure a life insurer's potential vulnerability to all surrenderable liabilities, it is necessary to review the impact of asset and liability 
maturations under normal and stressed cycles in the event of a crisis of confidence. A loss of confidence in the financial strength of an insurer on the part of distributors or policyholders, which can lead to a "run on the bank", can be triggered by adverse changes in the company's financial strength, the economy, the financial markets and/ or a company's media profile.

Operating performance An insurer's operating performance is an integral part of the overall rating analysis as it determines the insurer's ability to strengthen the balance sheet through earnings and hence positively influence financial strength. There is generally a greater emphasis on operating performance for insurers writing long-tail business. Conversely, operating performance is weighted less heavily for those insurers writing predominately short-tail business. A.M. Best reviews the components of a company's earnings over the past five-year period to make an evaluation of the sources of profits and the degree and trends of various profitability measures. Areas reviewed include underwriting, investments, capital gains/losses and total operating earnings, both before and after taxes. Profitability measures are easily distorted by operational changes. Therefore, A.M. Best reviews the mix and trends of premium volume, investment income and net income. The volatility of a company's earnings and the impact that this could have on capitalization and balance sheet strength is of particular concern to A.M. Best.

Business profile An insurer's business operation is important as it drives future earnings potential, which in turn influences future balance sheet strength. Business profile is influenced by the degree of risk inherent in the company's mix of business, an insurer's competitive market position and the depth and experience of its management. Lack of size or growth are not considered negative rating factors unless A.M. Best believes these issues have a negative influence on the company's prospective operating performance and balance sheet strength.

A.M. Best places greater emphasis on business profile issues for insurers writing longer duration business, such as life, retirement savings, casualty lines and reinsurance where long-term financial strength is critical. Especially at higher levels, what differentiates an insurer is the strength of its business profile, which typically translates into defensible competitive advantages. A.M. Best also analyses market risk, the potential risks associated with the market or business environment in which an insurer operates, as part of its assessment of business profile. This risk reflects the potential financial volatility that is introduced by, and associated with, the segment(s) of the insurance industry and/ or the financial services sectors within which an organization operates. Such risks may also be considered systemic risks and are generally common to all market participants (such as financial services reform, healthcare reform, expansion of alternative markets and the integration of healthcare providers). Insurance market risk can be biased either positively or negatively by a number of company-specific business factors.

Market risks can also be influenced by potential regulatory or legislative reforms, economic conditions, interest rates and financial market performance, as well as societal changes. For international companies and domestic insurers operating abroad, political climates, exchange and sovereignty risks may also have a significant bearing on market risk and are incorporated into A.M. Best's analysis. 


\section{Impairment rates}

A.M. Best has conducted a study on the long-term impairment rates of U.S. domiciled insurance companies (life/health and property/casualty). The definition of financial impairment is different from that of the issuer defaults generally used in the credit markets as the latter focuses on the non-payment of interest or principal. A.M. Best defines impairment as the first official action taken by a regulator. This could include involuntary liquidation, administrative order or any other action that restricts a company's ability to conduct its insurance business as normal.

The study (which covers data between 1977 and 2005) shows that insurers with a higher financial strength rating are less likely to become impaired than a vulnerable company (those with a Best's Financial Strength Rating below B +). There is also a correlation between the rating level and the time to impairment (Table 1).

\section{Reputational risks and risk management}

\section{What are reputational risks?}

A company's reputation is one of the most important assets it possesses. However, it is also one of the most difficult assets to protect. What is reputation and why does it play such a vital role for insurance companies?

The reputation of an organization is difficult to quantify. However, it is to a large extent linked to perceptions and opinions of interested parties or stakeholders. Although perceptions and opinions are subjective, they are formed as a result of an organization's behaviour or actions. Expectations of a company in terms of its actions and behaviour also vary from recipient to recipient. Whereas a customer's top priority is good service, the expectation of an investor is the delivery of shareholder value without much regard for customer service, although both expectations may be strongly correlated. Failure to meet expectations can negatively influence the perceptions of a company and result in a decline in its reputation.

For insurance companies, reputation plays an even greater role. Insurance is an intangible good and insurers (in order to be able to sell their products) are very much dependent on the trust of their customers that they will fulfill their obligations when a

Table 1 A.M. Best's impairment study. Impairment levels by rating category

\begin{tabular}{|c|c|c|c|c|c|}
\hline \multicolumn{6}{|c|}{ Impairment probability } \\
\hline Rating & 1-Year & 2-Year & 3-Year & 4-Year & 5-Year \\
\hline $\mathrm{A}++/ \mathrm{A}+$ & $0.06 \%$ & $0.20 \%$ & $0.37 \%$ & $0.55 \%$ & $0.73 \%$ \\
\hline $\mathrm{A} / \mathrm{A}-$ & 0.21 & 0.59 & 1.09 & 1.61 & 2.21 \\
\hline $\mathrm{B}++/ \mathrm{B}+$ & 0.66 & 1.74 & 2.86 & 4.18 & 5.55 \\
\hline $\mathrm{B} / \mathrm{B}-$ & 1.98 & 4.06 & 6.03 & 7.94 & 9.96 \\
\hline $\mathrm{C}++/ \mathrm{C}+$ & 3.39 & 5.66 & 8.48 & 11.20 & 13.51 \\
\hline $\mathrm{C} / \mathrm{C}-$ & 5.95 & 9.18 & 11.61 & 14.18 & 16.91 \\
\hline D & 7.44 & 12.56 & 17.33 & 21.54 & 25.66 \\
\hline
\end{tabular}


claim occurs or when a life policy expires. Any negative perception could impair new business production or trigger an increase in cancellations. Reputation and hence trust are therefore linked to the integrity of an insurance company driven by management actions, the quality of its sales forces, the handling of claims and the transparency of its products. While cash flow or capital problems can make an insurance company vulnerable, it is very often the loss of trust that is the underlying cause for financial difficulty. If market participants lose faith in the management's ability to control or turnaround the company, they forfeit any support. This could mean that investors do not provide additional capital when necessary, policyholders cancel their policies, brokers move business to other insurers or regulators step in (Figure 3).

\section{Reputation and trust - analytical issues}

\section{Trust as competitive advantage}

An insurance company that aims to be successful in a dynamic financial services environment must be trusted by its clients and potential clients. Trust means that something is deemed to be valuable. For an insurer, this means trust in a future promise to perform. Specifically, an insurer is trusted by its policyholders or potential clients to pay claims when called upon to do so.

Trust can be turned into a competitive advantage when insurers are able to build up a positive reputation. For example, governments with an overburdened state pension system are trying to shift the demographic risks to the private insurance sector. This

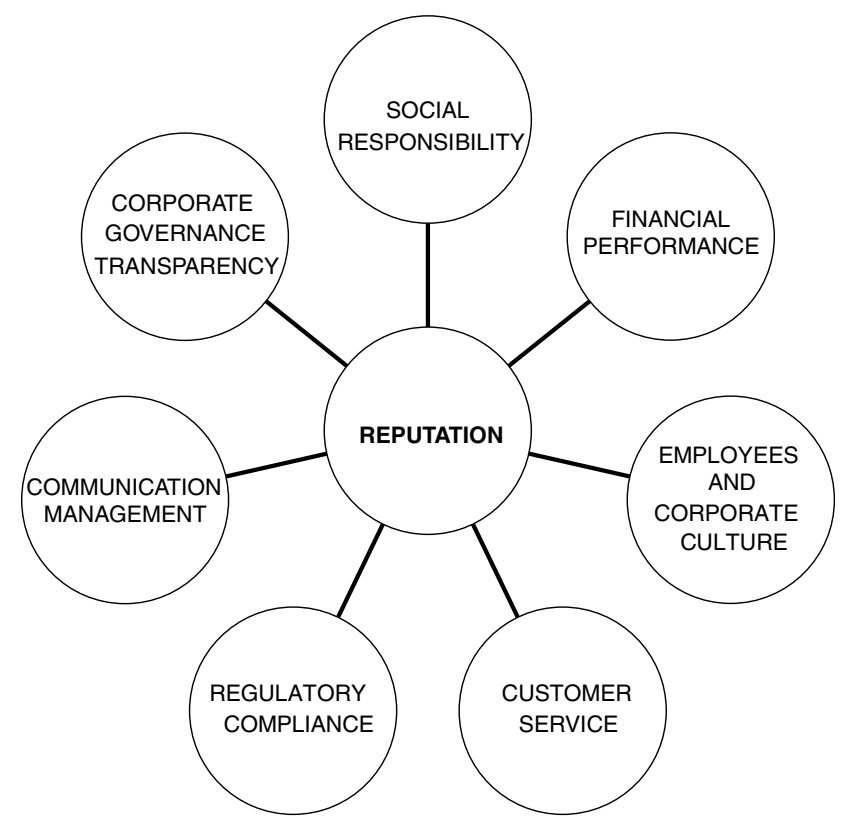

Figure 3. Reputational risks - potential sources. 
offers very good business opportunities for insurers who are trusted to fulfill their obligations. However, the enhancement of an organization's business profile also depends on whether it is able to define certain values and goals, which assist in building up trust. Notwithstanding this, all good intentions are worthless if the value statement of a company is not accompanied by appropriate actions and business conduct.

The competitive advantage can easily disappear if there is mistrust or a lack of confidence. For example, insurers who inflate their assets, show accounting irregularities or have to restate earnings could experience a negative impact on their reputation as these actions bring into question the overall business conduct of their management. Apart from the negative impact on the share price, a short-term loss of revenues combined with the long-term loss of customers could be the consequence.

\section{Earnings, capitalization and financial flexibility}

As mentioned above, a bad reputation can have a detrimental impact on a company's business position, which in turn can hamper a company's ability to generate earnings to support its capital position. Likewise, if insurers are able to build up a positive reputation they should be able to translate an enhanced business profile into stronger earnings. Over time, this should lead to an enhanced capitalization and eventually result in improved financial strength for the insurer. An increase in financial strength also has a "signal function" in the market and insurers could gain a competitive advantage out of this, with a better business profile and earnings leading to better ratings.

The reputation of an insurer can also impact its financial flexibility when a negative image could influence an investor's willingness to provide further funds. This not only applies to a negative reputation, due for example to inappropriate business conduct, but also when a company is not able to achieve its dividend targets. A bad reputation can also have a knock-on effect as one wrong action can act as a multiplier for other reactions.

\section{Reputation and trust in the rating process}

A.M. Best's financial strength ratings are an opinion of an insurer's ability to fulfill its obligations to policyholders. Ratings provide a prospective view, which involves an element of subjectivity. During the interactive rating process, rating analysts will meet management regularly to discuss an insurer's strategy, the company's market position and other issues pertinent to the financial strength of an insurer. Trust in an insurer's ability to achieve its strategic goals, be it financial targets or growth targets, plays an important role. Owing to the subjectivity of the more qualitative aspects of the rating analysis, the rating decision of a rating committee is partially driven by the credibility of its management. Credibility can be earned through actions, but also through a proven track record. For instance, where management tries to convince analysts that next year the company will finally achieve underwriting profits, when in the last five years an insurer has actually made losses, then the analysts will rightly be more sceptical as reputation is based on a perception deriving from either failure or success to achieve its growth, dividend and earnings targets. Failure to control underwriting in 
the past is likely to lead to a more sceptical view of prospective underwriting results, even if the management has taken drastic actions to avoid the negative experience of the past.

The experience and depth of management are important determinants for achieving success. As the insurance business is based on an underlying foundation of trust and fiscal responsibility, prudent management plays a more vital role than in most other industries. Competitive pressures within virtually every insurance market segment have amplified the importance of management's ability to develop and execute defensible strategic plans. A.M. Best's understanding of the operating objectives of a company's management team and its ability to achieve these objectives play an important role in the qualitative evaluation of the current and future operating performance of a company. In this context, the reputation of management, including its track record, play a significant role in the rating analysis (Figure 4).

Protection of the asset "trust" as part of the risk management process

As pointed out above, trust is an extremely important asset for insurers and this applies in particular to life insurance, which relies on the long-term investment of policyholders. Protecting this asset should, therefore, be an essential part of an insurer's risk management activities.

In the case of life insurers, their products are to a large extent sold by insurance companies rather than bought by policyholders, and are distributed either through their own sales force or through independent financial advisors. These distributors are, therefore, the first point of contact for potential customers and they will have to establish trust so that potential clients are willing to buy products from an insurer. Changes in the regulatory environment and higher requirements in terms of advice to clients makes it extremely important that insurers select and control their distribution channels more carefully. Any mis-selling of policies can not only negatively impact an insurer's reputation, but can also result in significant fines, thus influencing the company's operating performance.

The reputation of an insurer is built up by creating a culture where trust is maintained. The company culture is an important component of a firm's success

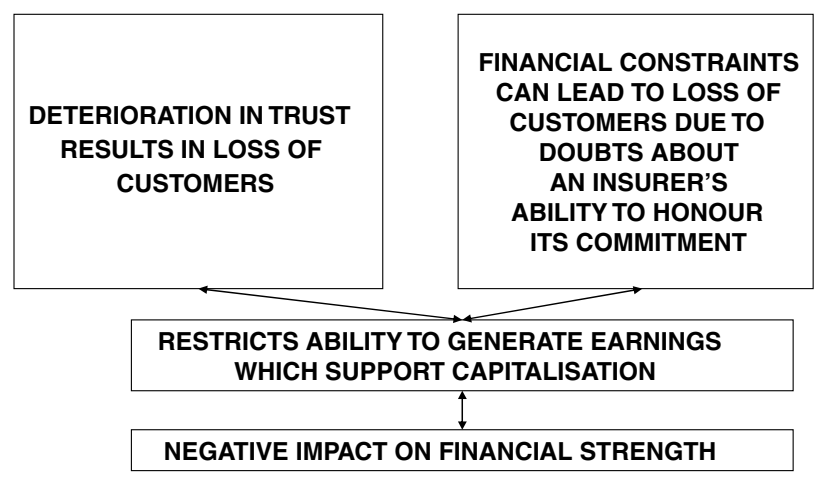

Figure 4. Financial strength and reputation. 
because it strongly influences the way things are done and the way activities are organized. Understanding the culture of a company gives an insight into how it will operate in the future. Insurers should learn how to establish and maintain an ethical environment, which allows them to manage the risks of unethical and illegal acts by employees, especially when they are part of their own sales force. Such an environment would minimize the possibility of non-compliance with laws and regulations, and is also an environment that guides and supports sound ethical decision-making as part of the corporate culture.

\section{Risks elements of an insurer}

Managing risks for third parties is the core business of insurers, which implies dealing with uncertainty. The ability and willingness to assume risks also requires from insurers that they are capable of managing risk internally through an orderly risk management process in order not to impair their capital base.

Generally, insurers provide cover for risks where the occurrence and the extent of a claim are uncertain, although the overall probability of claims happening and the total costs can be estimated using actuarial methods. Policyholders transfer their risks to insurers in order to remove the uncertainty about whether they have to pay for an event, such as flood, and when. In turn, insurers accept the risks for a premium. A simple promise to pay when a claim occurs triggers a number of risks on the insurer's side, which it must try to manage. The actuarial risks for property/casualty insurers concern mainly the underwriting risk (that is, the risk that premiums are not sufficient to cover claims either because of catastrophic events or because of higher than expected frequency) and reserving risk (the inadequacy of loss reserves for claims). In life/health, actuarial risks mainly comprise longevity, morbidity and catastrophic risks.

The other risk elements are similar for all insurers, although the importance of these elements may differ from insurer to insurer. Asset risks not only comprise the volatility of equity investments, but also the default risks of fixed income securities. The interest rate risk is particularly relevant for life insurers due to the potential asset/liability mismatching. Credit risk, in particular from reinsurers and operational risks, also plays an important role. The latter risk category is difficult to quantify and encompass, for example compliance risks and inadequate controls, which can impact the perception of an insurer in the market and thus influence its reputation (Figure 5).

Reputation and risk management When policyholders or potential clients start questioning the security of insurers due to overexposure to certain risks (such as in circumstances mentioned above), the reputation of an insurer can suffer. Existing life policyholders may decide to surrender their policies, placing a potential strain on liquidity on the insurer. In addition, potential new clients may look for alternative investments with other providers, which they perceive as more secure and reliable.

Inappropriate business practices can trigger regulatory intervention with negative consequences for the reputation of an insurer. Therefore, the control of exposure to sensitive products (such as mortgage endowments) is very important. The control 


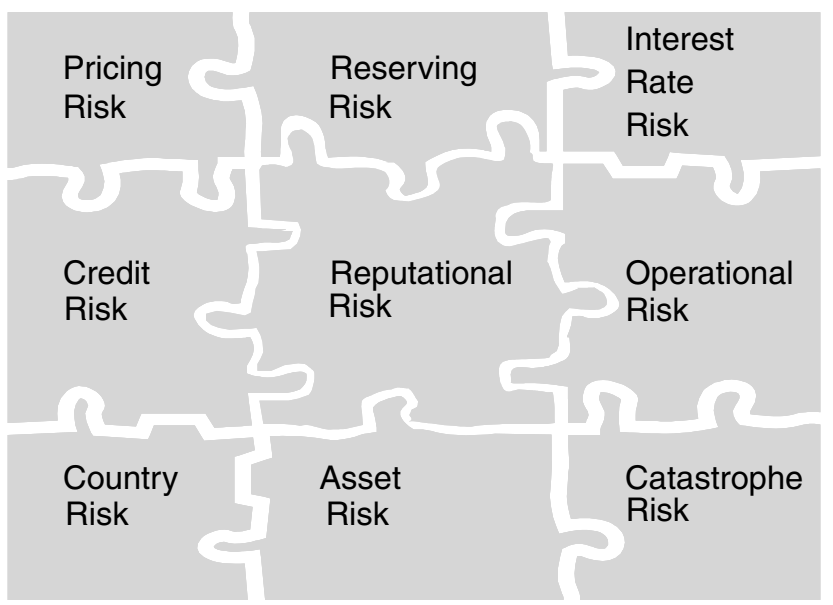

Figure 5. Examples of potential sources of risks.

should also extend to distribution channels as the first point of contact that a client may have with an insurer.

Inappropriate business practices can damage the reputation of an entire market, even if an individual insurer is compliant with all regulatory requirements. Market behaviour may draw an individual insurer into a crisis with a consequent negative impact on perception and reputation. Financial reinsurance is an example of a recent case where the behaviour of the whole market has triggered regulatory intervention.

Insurers therefore need to assess carefully all external factors that may have a negative impact on their reputation. In the context of risk management, a failure to do so could mean that insurers are not able to achieve certain strategic targets (such as growth or earnings for example). Therefore, a better understanding and better management of an insurer's risks (as compared to its competitors) may enable it to build up a competitive advantage.

Risk management, risk capital and earnings A natural extension of an insurer's risk management strategy is the measurement and allocation of capital. An insurer's core business is about taking risks and its management has to decide on the right risk/ return profile for the company, which requires measuring how much capital is available and allocated. This makes it important to understand risk as it defines the level of capital necessary to support the business, both now and in the future. Therefore, risk management can reduce capital requirements and also the volatility of earnings. As a result, this should have a positive impact on the stakeholders' trust of an insurer's management and its ability to control the company. Investors also assign a higher value to insurers with more consistent earnings as the risk rate for the cost of capital is determined by the volatility of earnings. Less volatile earnings will lead to lower capital charges, and investors may be more comfortable with the risks an insurer is writing (and which has a positive impact on financial flexibility).

The risk capital required based on an insurer's existing risk profile indicates to the company where it is overexposed or overconcentrated, and also where there are 
opportunities due to lower capital requirements in order to enhance the risk/return profile. Companies who write higher risks would have to achieve higher earnings and an insurer who reports the same earnings as its competitor, despite assuming higher underwriting risks, will be seen in a different light.

\section{Conclusion}

Reputational risk is one of the biggest threats for insurance companies. The promise to provide insurance cover or the promise to pay out an agreed sum at expiry or when an insured dies is based on the trust that a policyholder has in an insurer that it will be able and willing to honour its commitment. Any doubt in an insurer's commitment as a result of financial constraints, but also due to business practices (such as a deliberate delay in claims payments or in a mis-selling of products) could have a significant negative impact on its business profile.

In A.M. Best's view, the management of reputational risk is intrinsically linked to an insurer's overall risk assessment and risk control strategy. A.M. Best believes that property/casualty insurers will continue to be challenged by the emergence of new risks, such as electromagnetic fields, or by the increased frequency and severity of catastrophic risks. In life/health, the issue of improving longevity and increasing morbidity as a result of ageing populations is one of the main issues facing insurance companies.

An insurer's risk management strategy has, directly and indirectly, an influence on A.M. Best's main rating components: balance sheet strength, operating performance and business profile. As a result of the increased importance of risk management for the overall financial strength of an insurer, A.M. Best will place a greater emphasis on an insurer's ability to fully assess, monitor and control its risk. Insurers need to have the capabilities to adapt quickly to a fast changing business and risk environment. This also means not waiting until issues become apparent or a problem occurs, but to proactively identify future potential risks, which could threaten a company's business position, weaken its balance sheet or negatively impact its operating performance. A.M. Best believes that a strong risk management programme is necessary to support a higher rating, although that fact alone does not automatically lead to a better rating. Insurance companies can differentiate themselves from competitors through good risk management practices, which also protect the reputation of a firm. The ability to monitor and control risks should lead to stronger and less volatile earnings, thus positively influencing an insurer's balance sheet and improving an insurer's financial strength.

\section{Further reading}

A.M. Best (2006) A.M. Best Rating Methodology: Best's Impairment Rate and Rating Transition Study 19772005, Oldwick, NJ, USA (March), www.ambest.com.

A.M. Best (2006) A.M. Best Special Report: A.M. Best Comments on Enterprise Risk Management and Capital Models, Oldwick, NJ, USA (February), www.ambest.com.

A.M. Best (2006) A.M. Best Rating Methodology for Non-U.S. Domiciled Companies, Oldwick, NJ, USA, 2005 Edition, www.ambest.com. 
Baglini, N.A. (2001) 'Ethical behaviour, corporate culture and financial services', in W. Kielholz and P. Liedtke (eds) Strategic Issues in Insurance, Essays in Honour of Orio Giarini, Oxford: Blackwell Publishers, pp. 7-12.

Economist Intelligence Unit (2005) Reputation: Risk of risks, Global Risk Briefing, EIU White paper (December), www.eiu.com.

Forbes, S.W. et al. (2001) Enterprise Risk Management in the Life Insurance Industry, Atlanta GA: LOMA, www.loma.org.

Gregory, C. (2003) Minimizing Enterprise Risk, A Practical Guide to Risks and Continuity, London: FT Prentice-Hall.

Jablonowski, M. (2006) 'The real value of ERM', Risk Management Magazine 53(2): 32-37.

Lichtenberg, A.P. and Hoyt, R.E. (2003) 'The determinants of enterprise risk management: evidence from the appointment of chief risk officers', Risk Management \& Insurance Review 6(1): 37-52.

Murray, K. (2003) 'Reputation - managing the single greatest risk facing business today', Journal of Communication Management 8(2): 142-149.

O'Rourke, M. (2004) 'Protecting your reputation', Risk Management Magazine 51(4): 14-18.

PriceWaterhouseCoopers (2004) Enterprise-Wide Risk Management for the Insurance Industry, Global Study, pp. 1-69, www.pwc.com.

Rayner, J. (2003) Managing Reputational Risk: Curbing Threats, Leveraging Opportunities, Chichester: John Wiley \& Sons.

Shaw, J. (2005) 'Managing all of your enterprise's risks', Risk Management Magazine 52(9): 23-30.

Schüwiller, T. (2004) 'The Faces of Reputation', in Etudes et dossiers, 2nd Meeting of the Geneva Association's Global Insurance Communications Network, Zurich 6 - 7 December 2004.

Schwamm, H. (2005) 'Reputation risk - the biggest risk banks and insurance companies face today', Risk Management Newsletter 38(Nov): 5-7, Geneva Association Information Newsletter (Nov.).

Tillinghast-Towers Perrin (2000) Enterprise Risk Management, An Analytical Approach (January), pp. 1-38.

Tillinghast-Towers Perrin (2001) Risk Value Insights, Creating Value Through Enterprise Risk ManagementA Practical Approach for the Insurance Industry (June), pp. 1-94.

Tillinghast-Towers Perrin (2005) Adding Value Through Risk and Capital Management: An ERM Update on the Global Insurance Industry (February), pp. 1-42.

\section{About the Author}

Michael Zboron has been a Managing Senior Financial Analyst for A.M. Best for the past four years. He heads up a team of pan-European analysts and is the lead analyst for several major insurance groups. Michael Zboron holds a degree in Business Administration and Economics from the University for Applied Sciences in Münster and a Master of Science degree in Insurance and Risk Management from the City University. 